\title{
Using administrative health data for the surveillance of interventions for alcohol-related harm among young people
}

\author{
Steve Kisely MD PhD, Mark Asbridge PhD, Jason Connor PhD, Angela White PhD, Joanne Pais MSc, \\ Elizabeth Lin PhD
}

$\mathrm{T}$ here are growing concerns about problem drinking among young people in Canada. In a 2009 survey, almost $60 \%$ of Canadians between the ages of 15 and 24 years reported consuming alcohol in the previous month. ${ }^{1}$ Of these respondents, $22 \%$ reported episodes of heavy drinking, and 20\% reported having suffered alcohol-related harms in a lifetime. This is not a problem unique to Canada. In Australia, $52 \%$ of all serious road injuries and $32 \%$ of hospital admissions for people aged 15-24 years are the result of misuse of alcohol. ${ }^{2}$

Here, we examine the role and utility of routine administrative health data in the surveillance of both alcohol-related harm and interventions to reduce the impact of alcohol among young people. Administrative data, that is data that are routinely collected such as ambulance use or presentations to hospital, are available, but are not now being used to the fullest extent for this purpose. Our analysis was informed by a search for peer-reviewed articles through MEDLINE (January 1950 to November 2010) and grey literature through Google, as well as the bibliographies of retrieved articles. Box 1 lists the search terms that we used. We excluded patient surveys, and the search was restricted to articles published in English. Our search returned 155 articles, and we selected what we considered to be the 18 most relevant to inform this paper.

\section{Assessing harm reduction for young people}

Measures to reduce the health and social costs associated with the high-risk consumption of alcohol include reducing its availability (i.e., by reducing its physical availability or by increasing its price), changing the context in which drinking occurs, controlling advertising for alcohol products or controlling the use of motor vehicles. ${ }^{3}$ The best evidence of effective harm reduction concerns policies to restrict alcohol's affordability and physical availability. ${ }^{4}$
However, it is difficult to consistently assess and compare the impact of harm reduction interventions. Most studies provide estimates that are snapshots of mortality and morbidity caused by alcohol, but comparisons have been restricted because of differing assumptions, methods and time points. Longitudinal studies, such as the National Alcohol Indicators Project in Australia, ${ }^{5}$ have focused on data concerning admissions to hospital, which is a limitation considering that most alcohol-related conditions do not result in that outcome. ${ }^{6,7}$

Sources of information on the effect of interventions include health surveys and administrative data, as well as information from police and criminal justice databases (Appendix 1, available at www.cmaj.ca/cgi/content/full/cmaj.110367 (DC1). ${ }^{8}$

Administrative data include data on ambulance use or presentations to hospital. For example, $10 \%-18 \%$ of presentations to the emergency department are due to alcohol, although some studies have reported rates as high as 30\%. ${ }^{9}$ Information from police or criminal justice databases could include public order offences, assaults and convictions for impaired driving involving young people. ${ }^{10,11}$ Data from police and ambulance services can also provide information about where an injury or offence occurred. This can be useful for
Competing interests: None declared.

This article has been peer reviewed.

Correspondence to:

Dr. Steve Kisely,

s.kisely@uq.edu.au

CMAJ 2012. DOI:10.1503 /cmaj.110367

- KeY POINTS

- Growing concern about binge drinking in young people has led to a range of policy initiatives and community-based programs to reduce alcohol's impact on this age group.

- Surveillance techniques, originally applied to communicable disease, can be employed to investigate the occurrence, trends and distribution of alcohol-related diseases and harm.

- Administrative data are routinely collected and are thus particularly suitable for surveillance.

- The choice of measures for evaluating interventions for young people should be appropriate to this group, and surveillance should include a range of acute alcohol-related health indices, such as unintentional and intentional injuries, rather than chronic medical conditions such as cirrhosis, which are markers of the long-term impact of alcohol consumption among adults. 
evaluating local interventions such as increased policing targeted to specific locations.

Population-based studies of interventions to reduce alcohol-related harm have generally relied on administrative data concerning traffic collisions, homicides and other forms of violence, ${ }^{4,12,13}$ or on long-term diseases such as cirrhosis, cardiovascular disorders and cancers. Such measures are less appropriate markers of problematic consumption among young people. ${ }^{14}$ Furthermore, chronic conditions such as cirrhosis, cancer and alcohol dependence cannot be used to assess the short-term impact of policy.

For more acute disorders, mental health conditions such as alcohol abuse constitute only a small number of presentations to hospital by young people that can be attributed to alcohol. For example, among 15 to 24 year olds, unintentional and intentional injuries are the most common causes of alcohol-related admissions to hospital for both men (66\%) and women (59\%), followed by poisoning and sexual assualt. ${ }^{15}$

It is important to choose measures of alcoholrelated harm that are reliable across jurisdictions, sensitive to change and tailored to specific policy interventions.

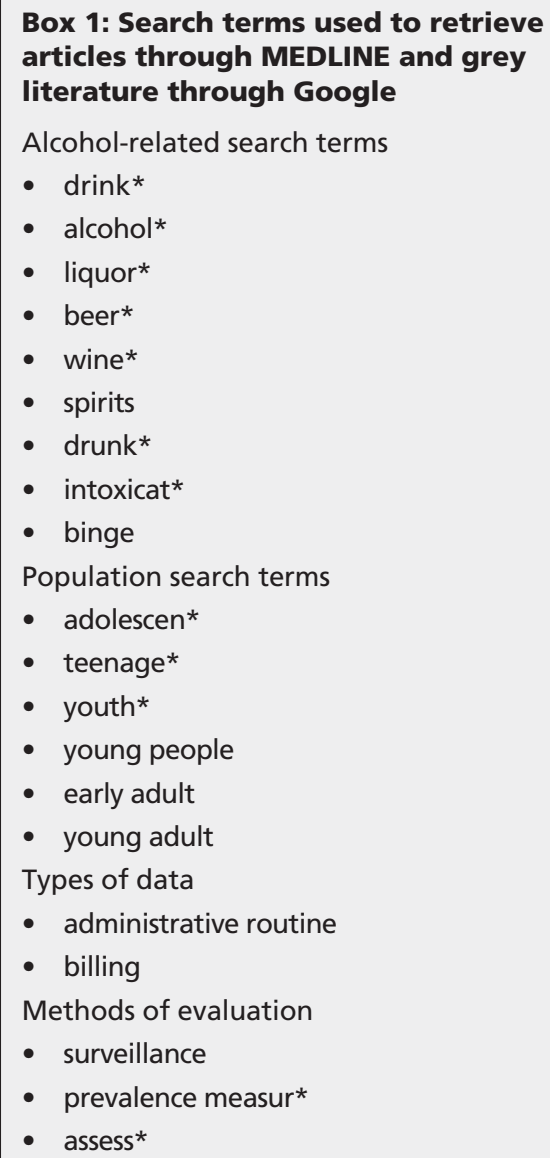

\section{The role of administrative data}

Administrative data records, which are routinely collected by, for example, governments and hospitals, allow complex analyses of risk factors and outcomes, such as linkage across multiple datasets, rather than summary indicators such as those published by the Canadian Institute for Health Information. ${ }^{16}$ Surveillance is the ongoing, systematic use of such data to identify trends, associations and predictors of health outcomes. Surveillance was originally applied to communicable disease, but now extends to mental illness, diabetes, arthritis, cancer and circulatory and other diseases. For example, a standard case definition for the surveillance of psychiatric disorders has been adopted by the Public Health Agency of Canada. ${ }^{17}$

Surveillance systems can also be applied to assess disorders involving the use of alcohol or other substances and their associated harms. One example is the Australian Illicit Drug Reporting System, which triangulates data from the Australian Customs and Border Protection Service and data on overdoses and seizures, as well as responses to the National Household Surveys of Drug Use. ${ }^{18}$

Administrative data are particularly suitable for surveillance because they provide ongoing information in a way that is practical, uniform, cost-effective and sensitive to change. Data on trends, especially, can provide a useful framework for understanding drinking cultures.

The analyses of linked datasets can prove even more powerful since use across different services can be examined in terms of both patterns and changes over time. Creating a "lifebook" of events across different providers of care, rather than just one episode with a single provider, enables the investigation of health outcomes as dynamic processes rather than static events. Such linkages are only possible for person-based records with a unique identifier, such as a health card number encrypted to preserve anonymity and stripped of any identifying information before its release to researchers.

Most administrative data in Canada are collected by provinces. Databases relevant to the surveillance of alcohol-related disorders include those concerning admissions to and discharges from hospital, physician billings and ambulatory care (Table 1). Trauma registries and data from ambulance services are also useful (Table 1).

In Australia, administrative data concerning presentations to the emergency department have been used to evaluate a recent increase in tax on "premixed" alcoholic beverages. ${ }^{4}$ These beverages are generally preferred by teenagers over 
other forms of alcohol. ${ }^{19}$ Interrupted time series of pilot data from the Gold Coast, Queenland, a favoured destination for young people, indicate no decrease in alcohol-related presentations to the emergency department during the 12 months after the increase in taxes. ${ }^{20}$ These results suggest no change in the levels of problem drinking and are reflected in Australia-wide sales data, where the decline in the sale of premixed beverages was associated with increases, though to a lesser degree, in the sales of other types of alcoholic beverages. ${ }^{21}$ This information suggests that young people may have substituted premixed beverages with other forms of alcohol.

\section{Limitations of using adminstrative data}

Coverage and availability of administrative data may vary by province. Because these data are restricted to demographic, diagnostic and treatment information for formally funded services, analyses are often restricted to the data collected from people presenting for treatment. There are few, if any, direct measures of the severity of disease, disability or outcomes such as recovery, wellness or quality of life.

Some administrative data may be restricted to primary diagnoses and lack secondary codes where alcohol-related disorders may have a higher probability of being recorded..$^{22}$ Moreover, alcohol is tested for inconsistently in the emergency department, and testing rates vary considerably across time, institutions and provinces. ${ }^{23}$ This means that alcohol as a factor in trauma must be inferred by other means, such as the analysis of presentations to the emergency department for injuries on evenings or weekends, ${ }^{9}$ the investigation of specific types of injury relevant to the consumption of alcohol (e.g., traffic accidents, falls and assaults) ${ }^{24}$ or the use of alcohol-attributable fractions, ${ }^{25}$ where the likelihood that a given condition is associated with alcohol is calculated using previously published clinical data. Alcoholic cirrhosis, for example, has an alcohol-attributable fraction of 1.0.25

Even using these methods, it is almost impossible to exclude the influence of other substances such as psychostimulants or depressants of the central nervous system. Recognizing that some degree of measurement error is associated with administrative data, the use of international diagnostic codes such as the clinical modification of the International Classification of Diseases, 9th revision (ICD-9-CM), or the International Statistical Classification of Diseases and Related Health Problems, 10th revision (ICD-10), may assist with comparability over time and across jurisdictions. The Public Health Agency of Canada has shown that, in the related area of mental health, a case definition for psychiatric disorder was stable across province and time and was consistent with the prevalence measured using data from community surveys. ${ }^{17}$

\section{Alternative sources of data}

Clinical charts and electronic medical records often contain detailed information, but data retrieval from these sources is both time consuming and expensive. Self-reported data from surveys vary in quality and are subject to nonresponse and

Table 1: Canadian databases relevant to the surveillance of alcohol-related disorders

\begin{tabular}{|c|c|}
\hline Potential dataset & Relevant information \\
\hline Discharge Abstract Database & Admissions to hospital for alcohol-related conditions \\
\hline Ontario Mental Health Reporting System & Admissions to hospital for alcohol-related conditions \\
\hline Med-Écho (Quebec) & Admissions to hospital for alcohol-related conditions \\
\hline National Ambulatory Care Reporting System & $\begin{array}{l}\text { Presentations to the emergency department related to } \\
\text { alcohol }\end{array}$ \\
\hline $\begin{array}{l}\text { National and provincial trauma registries } \\
\text { (e.g., the Canadian Hospitals Injury } \\
\text { Reporting and Prevention Program database, } \\
\text { which focuses on pediatric presentations) }\end{array}$ & Trauma presentations \\
\hline Emergency health services data & Ambulance call outs and attendances \\
\hline Provincial billing data & Visits to physicians \\
\hline $\begin{array}{l}\text { Mental health clinician contacts in publicly } \\
\text { funded services as captured by the Mental } \\
\text { Health Outpatient Information System in } \\
\text { Nova Scotia (until 2006) and the Community- } \\
\text { Based Psychiatry Services database in British } \\
\text { Columbia }\end{array}$ & Community-based mental health care \\
\hline
\end{tabular}


recall bias, ${ }^{26}$ problems particularly relevant to the measurement of alcohol-related harms. ${ }^{27}$ People who consume alcohol more heavily may be underrepresented in surveys, as they may be in hospitals, intoxicated or inaccessible in other ways. Because surveys have diminishing rates of response and are expensive, they are done infrequently.

Data on sales and taxation of alcohol have also been used to assess longitudinal and regional trends in alcohol use and, by proxy, the effectiveness of alcohol policy. ${ }^{28}$ However, such data only indicate what and how much was purchased, not who bought it, how it was used or the consequences of its use. ${ }^{29}$ Data on taxation and sales also only reflect overall consumption, not the amount of drinking done at risky levels. ${ }^{30}$ Finally, although data can be broken down by sales of spirits, wine and beer, they do not capture changes in alcohol content within a type of beverage. ${ }^{31}$ For example, the alcohol content of wine in Australia and the United States has gradually increased since the late 1980 s. $^{31}$

\section{Next steps}

Work done by the Public Health Agency of Canada in the areas of diabetes and mental health provides a model for a national surveillance system that could be extended to alcohol-related harm among young people. Initially, a standard case definition is agreed upon (usually contact with the health service for a given range of codes from the ICD-9-CM or ICD-10 over a defined period). For diabetes, it is at least one admission to hospital, or two visits to a physician, within two years. For mental health, it is at least one admission to hospital or one visit to a physician for ICD-9-CM codes 290-319 within one year. Levels of alcohol-related harm among young people can also be estimated by applying alcohol-attributable fractions to administrative data. Alcohol-attributable fractions for presentations to the emergency department already exist in Britain and Australia. ${ }^{20,25}$

It is important to choose measures of alcoholrelated harm that are relevant to young people such as unintentional and intentional injuries. ${ }^{15}$ Unintentional injuries are not deliberate (e.g., poisonings, falls and traffic-related injuries). Intentional injuries are deliberately inflicted, whether to oneself or by another individual (e.g., self harm and physical or sexual assault).

Data should be collected from a range of sources before and after a change in policy and should include one or more control series. Outcomes should be sufficiently common or the jurisdiction large enough to have adequate statistical power. Comparability with definitions used internationally such as in Britain or Australia would be an added benefit..$^{20,25}$

The next step is to test the case definition by determining the prevalence of alcohol-related harm in pilot jurisdictions and comparing rates across age, sex, time and geography. Sensitivity analyses can be used to investigate the effect of varying the case definition. One sensitivity analysis would be of narrow and broad definitions of alcohol-related harms based on alcoholattributable fractions appropriate to young people. Another example would be an analysis restricted to presentations at the emergency department that occurred at night and on weekends. A third sensitivity analysis would be to vary the time within which a presentation could occur, for example two years instead of one. Once a case definition was agreed to by all provinces and territories, it could be applied across Canada. For this to occur, the collection of data must be standardized. Currently, different regions, even within the same province, use different approaches, and some still use paperbased systems.

Equally important, the contribution of alcohol to trauma would be better understood through greater compliance to testing for alcohol in emergency departments and capturing the results of these tests through administrative data. Even where testing is mandatory, it is not consistently practised; some jurisdictions had rates as low as $50 \%$ in the years after mandatory screening for alcohol was introduced..$^{23}$ Instead of screening, health professionals relied on obvious signs of intoxication or targeted groups such as young people and men, suggesting that better staff education is necessary to improve testing rates. Testing could also provide an opportunity for a brief alcohol intervention.

\section{Conclusion}

Routine administrative data can make substantial contributions to the surveillance of alcohol-related harms to health across jurisdictions and within target populations. Their timeliness, accessibility, large sample size and jurisdictional spread create the potential to improve the quality of currently available information on alcohol-related harm. Along with sales data and longitudinal surveys at the population level, such as the Canadian Alcohol and Drug Monitoring Survey, ${ }^{1}$ administrative data would provide a more comprehensive, dynamic picture of trends in the consumption of alcohol and its related harms in Canada. Equally important, administrative health data can make an important contribution to the development, monitoring and evaluation of a range of alcohol-related policies, 
both provincial and national. The Public Health Agency of Canada has established similar surveillance systems for diabetes and mental health at minimal cost. Thus, the structure and expertise needed already exist. What is required is the political will to implement them.

\section{References}

1. Health Canada. Canadian alcohol and drug use monitoring survey: summary results for 2009. Ottawa (ON): Health Canada; 2010.

2. Chikritzhs T, Stockwell T, Heale P, et al. Trends in alcoholrelated road injury in Australia, 1990-1997. National Alcohol Indicators, Bulletin No 2. Perth (Australia): National Drug Research Institute, Curtin University of Technology; 2000. Available: http://ndri.curtin.edu.au/local/docs/pdf/naip/naip002 .pdf (accessed 2011 Apr. 4).

3. World Health Organization. Global status report: alcohol policy country profiles. Geneva (Switzerland): WHO Department of Mental Health and Substance Abuse; 2004.

4. Wagenaar AC, Salois MJ, Komro KA. Effects of beverage alcohol price and tax levels on drinking: a meta-analysis of 1003 estimates from 112 studies. Addiction 2009;104:179-90.

5. National Drug Research Institute. The National Alcohol Indicators Project (NAIP). Perth (Australia): The Institute, Curtin University of Technology; 2011. Available: http://ndri.curtin.edu.au /research/naip.cfm (accessed 2011 Apr. 4).

6. Pirmohamed M, Brown C, Owens L, et al. The burden of alcohol misuse on an inner-city general hospital. QJM 2000;93:291-5.

7. World Health Organization. Alcohol and injury in emergency departments: summary of the report from the WHO Collaborative Study on Alcohol and Injuries. Geneva (Switzerland): The Organization; 2007.

8. Brinkman S, Chikritzhs T, Stockwell T, et al. An indicator approach to the measurement of alcohol-related violence. In: Williams P, editor. Alcohol, young persons and violence. Australian Institute of Criminology Research and Public Policy Series. No. 35. Canberra: (Australia): Australian Institute of Criminology; 2001. p. 61-84. Available: www.aic.gov.au/documents/0/9 /E/\%7B09E08D01-F508-4FB1-85AB02A990A17AE2\%7DRPP 35.pdf (accessed 2011 Apr. 4).

9. Humphrey G, Casswell S, Han DY. Alcohol and injury among attendees at a New Zealand emergency department. $N$ Z Med $J$ 2003; 116:U298

10. Herttua K, Makela P, Martikainen $\mathrm{P}$, et al. The impact of a large reduction in the price of alcohol on area differences in interpersonal violence: a natural experiment based on aggregate data. J Epidemiol Community Health 2008;62:995-1001.

11. Wagenaar AC, Wolfson M. Deterring sales and provision of alcohol to minors: a study of enforcement in 295 counties in four states. Public Health Rep 1995;110:419-27.

12. Asbridge M, Mann R, Smart R, et al. The effects of Ontario's administrative driver's licence suspension law on total driver fatalities: a multiple time series analysis. Drugs Educ Prev Policy 2009;16:140-51

13. Fell JC, Fisher DA, Voas RB, et al. The impact of underage drinking laws on alcohol-related fatal crashes of young drivers. Alcohol Clin Exp Res 2009;33:1208-19.

14. Mann RE, Smart RG, Govoni R. The epidemiology of alcoholic liver disease. Alcohol Res Health 2003;27:209-19.

15. Elder RW, Shults RA, Swahn MH, et al. Alcohol-related emergency department visits among people ages 13 to 25 years. J Stud Alcohol 2004;65:297-300.

16. Canadian Institute for Health Information (CIHI). Health indicators 2010. Ottawa (ON): The Insitute; 2010.

17. Kisely S, Lin E, Lesage A, et al. Use of administrative data for the surveillance of mental disorders in five provinces. Can J Psychiatry 2009;54:571-5.

18. Hall W, Degenhardt L. The Australian Illicit Drug Reporting System: Monitoring trends in illicit drug availability, use and drug-related harm in Australian 1996-2006. Contemp Drug
Probl 2009;36:643-61.

19. Australian Institute of Health and Welfare. 2007 National drug strategy household survey: first results. Canberra (Australia): The Institute; 2008.

20. Kisely S, Pais J, White A, et al. How routine data can measure the effectiveness of policies to reduce binge drinking in young people on the Gold Coast. Proceedings of the Gold Coast Health and Medical Research Conference; 2010 Dec 2-3; Australia: Griffith Health Institute; 2010. Available: www.griffith.edu.au/_data /assets/pdf_file/0010/264295/2010-GCHMRC-book-FINAL.pdf (accessed 2011 Apr. 4)

21. Australian Bureau of Statistics. Apparent consumption of alcohol, Australia, 2008-09. Canberra (Australia): The Bureau; 2010. Available: www.abs.gov.au/AUSSTATS/abs@.nsf/Lookup /4307.0.55.001Main+Features12008-09?OpenDocument (accessed 2011 Apr. 4).

22. Canadian Institute for Health Information (CIHI). Mental health and addiction services: prototype indicator report. Ottawa (ON): The Institute; 2001.

23. Rootman DB, Mustard R, Kalia V, et al. Perceptions and realities of testing for alcohol and other drugs in trauma patients. J Trauma 2007;63:1370-3.

24. Canadian Institute for Health Information (CIHI). Ontario trauma registry bulletin: alcohol-related major injury hospitalizations in Ontario, 2000/2001. Ottawa (ON): The Institute; 2002.

25. Jones L, Bellis M, Sumnall H, et al. Alcohol-attributable fractions for England: Alcohol-attributable mortality, and hospital admissions. Liverpool (UK): North West Public Health Observatory (NWPHO), Liverpool John Moores University; 2009.

26. Groves RM. Nonresponse rates and nonresponse bias in household surveys. Public Opin Q 2006;70:646-75.

27. Zhao J, Stockwell T, Macdonald S. Non-response bias in alcohol and drug population surveys. Drug Alcohol Rev 2009;28:648-57.

28. Hall WD, Chikritzhs TN, d'Abbs PH, et al. Alcohol sales data are essential for good public policies towards alcohol. Med J Aust 2008;189:188-9.

29. Smith PF, Remington PL, Williamson DF, et al. A comparison of alcohol sales data with survey data on self-reported alcohol use in 21 states. Am J Public Health 1990;80:309-12.

30. Rehm J, Kehoe T, Gmel G, et al. Statistical modeling of volume of alcohol exposure for epidemiological studies of population health: the US example. Popul Health Metr 2010;8:3.

31. Chikritzhs TN, Allsop SJ, Moodie AR, et al. Per capita alcohol consumption in Australia: will the real trend please step forward? Med J Aust 2010;193:594-7.

Affiliations: From the School of Population Health (Kisely, Pais), the Centre for Youth Substance Abuse Research (Connor, White) and the Discipline of Psychiatry (Connor), University of Queensland, Brisbane, Australia; the Department of Community Health and Epidemiology (Kisely, Asbridge), Faculty of Medicine, Dalhousie University, Halifax, NS; the Health Systems Research and Consulting Unit, Centre for Addiction and Mental Health, and the Institute for Clinical Evaluative Sciences (Lin), Toronto, Ont.

Contributors: Steve Kisely had the original idea for the paper, developed and performed the search and wrote the first and final drafts of the manuscript. All of the authors revised the manuscript critically for important intellectual content and approved the final version submitted for publication.

Funding: The Institute for Clinical Evaluative Sciences (ICES) and the Centre for Addiction and Mental Health $(\mathrm{CAMH})$ are supported through annual funding from the Ontario Ministry of Health and Long-Term Care (MOHLTC). The opinions, results and conclusions reported in this paper are those of Dr. Lin and are not necessarily those of the funding sources. No endorsement by ICES, $\mathrm{CAMH}$ or the Ontario MOHLTC is intended or should be inferred. 